Supporting Information

\title{
Synthesis of High Molecular Weight Poly(phthalazinone ether)s by Ullmann C-N and C-O Coupling Reactions
}

\author{
Jinyan Wang, ${ }^{\dagger, *}$ Yan Gao, ${ }^{\dagger}$ Antisar R. Hlil, ${ }^{\dagger}$ Allan S. Hay ${ }^{*}{ }^{\dagger}$ \\ ${ }^{\dagger}$ Department of Chemistry, McGill University, 801 Sherbrooke Street W., Montreal, Quebec, H3A \\ 2K6, Canada \\ * Department of Polymer Science \& Materials, Dalian University of Technology, 158 Zhongshan \\ Road, Dalian, 116012, P. R. China
}

\section{Experimental Section}

Materials. 1, 2-dihydro-4-(4-hydroxyphenyl)-1-(2H)-phthalazinone(DHPZ) was supplied by Dalian Polymer New Material Company. Quinoline was purified by distillation under vacuum. Commercial cuprous chloride was dissolved in concentrated hydrogen chloride and the resulting solution was filtered through an acid funnel to remove the insoluble substance. The liquid obtained was then diluted by pure water then to collect the white precipitate. The white solid was washed by methanol and ether, respectively, and then kept in a desiccator. Others chemicals were purchased from Aldrich and used as received.

Characterization. ${ }^{1} \mathrm{H}$ NMR spectra were recorded on a Varian Unity 400 instrument $(400 \mathrm{MHz})$, and $\mathrm{CDCl}_{3}$ was used as solvent. TMS was used as reference for ${ }^{1} \mathrm{H}$ NMR spectra. Inherent viscosities were measured in a Ubbelohde viscometer at a concentration of $0.5 \mathrm{~g} / \mathrm{dL}$ in NMP at 30 $\pm 1{ }^{\circ} \mathrm{C}$. The bath temperature was controlled using a Julabo ( model PC) heater. Molecular weight and $M_{w}$ distribution were measured by gel permeation chromatography (GPC) on a Waters 510

\footnotetext{
* Corresponding author. Email: allan.hay@mcgill.ca

$\uparrow$ McGill University.

$\ddagger$ Dalian University of Technology.
} 
system equipped with three consecutive polystyrene gel columns (Phenomenex Phenogel 5um 500 $\AA$ A, $5 \mu \mathrm{m} 10^{4} \AA$, and $5 \mu \mathrm{m}$ Linear/Mixed) eluted with chloroform at a flow rate of $1.0 \mathrm{~mL} / \mathrm{min}$ calibrated by standard polystyrenes. Glass transition temperatures $\left(T_{g}\right)$ of polymers were detected by differential scanning calorimetry (DSC) with a Seiko $220 \mathrm{DSC}$ at a heating rate of $10{ }^{\circ} \mathrm{C} / \mathrm{min}$ with $160 \mathrm{~mL} / \mathrm{min}$ gas flow. The weight loss data were obtained from a Seiko $220 \mathrm{TG} / \mathrm{TGA}$ instrument at a heating rate of $20^{\circ} \mathrm{C} / \mathrm{min}$ in nitrogen with $220 \mathrm{~mL} / \mathrm{min}$ gas flow rate.

Preparation of Catalyst: $1.5 \mathrm{~g}(0.11 \mathrm{~mol})$ of white cuprous chloride was added to $10 \mathrm{~g}$ of freshly distilled quinoline in a $25 \mathrm{~mL}$ flask in the protection of argon atmosphere. The red mixture was vigorously stirred at $25^{\circ} \mathrm{C}$ for $48 \mathrm{hr}$. The dark red decanted liquid was collected for use as catalyst.

\section{Polymer Synthesis}

Synthesis of Polymer 5a3: A 25 mL, 3-necked round-bottomed flask equipped with a Dean-Stark trap, condenser, inert gas inlet, magnetic stirrer, was charged with 1,2-dihydro-4-(4-hydroxyphenyl)-1-(2H)-phthalazinone(DHPZ) (1.1900 g, $5 \mathrm{mmol}$ ), potassium carbonate $(0.9660 \mathrm{~g}, 7 \mathrm{mmol})$, sulfolane $(6 \mathrm{~mL})$ and chlorobenzene $(10 \mathrm{~mL})$. The mixture was heated to $145^{\circ} \mathrm{C}$ (oil bath) under an argon atmosphere and maintained at this temperature for $4 \mathrm{hr}$ to remove water produced during the reaction. After complete dehydration, the reaction temperature was increased to $190-195^{\circ} \mathrm{C}$ (oil bath) and the chlorobenzene was distilled. The yellow slurry in the flask was cooled to $80^{\circ} \mathrm{C}$ and $1.6405 \mathrm{~g}(5 \mathrm{mmol})$ of 4,4'-dibromodiphenyl ether was carefully added. The reaction mixture was then heated to $190-195^{\circ} \mathrm{C}$. The above-obtained $\mathrm{Cu}(\mathrm{I}) \mathrm{Cl} /$ quinoline catalyst $(0.5 \mathrm{~mL})$ was injected into the reaction mixture. The resulting mixture was maintained at this temperature for $17 \mathrm{hr}$, after which time, the color of reaction solution became dark brown, indicating that the potassium salt of DHPZ had almost gone into solution. $8 \mathrm{mg}$ of dry cuprous chloride powder was fed into the reaction. The reaction mixture was stirred at $190-195{ }^{\circ} \mathrm{C}$ for 
another $24 \mathrm{hr} .5 \mathrm{~mL}$ of DMSO was added to dilute the reaction solution after the reaction was cooled to $100{ }^{\circ} \mathrm{C}$ and the solution was poured into the mixture of methanol and water $(\mathrm{v} / \mathrm{v}=10: 1)$ in the presence of some dilute $\mathrm{HCl}$. The white precipitate was isolated by filtering and placed in 200 $\mathrm{mL}$ of deionized water to boil for $1 \mathrm{hr}$. The dried precipitate was dissolved in chloroform. The polymer solution was filtered through Celite and reverse-precipitated with acetone. The precipitate was re-dissolved in chloroform and re-precipitated in methanol. After collecting the polymer, it was dried in a vacuum oven at $100^{\circ} \mathrm{C}$ overnight.

Polymers 5a1, 5a2, 5a4, were prepared via a similar procedure. The only exception was that the reaction was maintained at the designated temperature as shown in Table $\mathbf{1}$ after the complete dehydration.

The preparations of the polymers $\mathbf{5 b 1}, \mathbf{5 c}, \mathbf{5 d}, \mathbf{5 e}, \mathbf{5 f}$ and $\mathbf{5 g}$ also followed the above-described procedure.

Polymers $5 \mathbf{a} 3\left(400 \mathrm{MHz}, \mathrm{CDCl}_{3}\right): \delta(\mathrm{ppm}) 8.59(\mathrm{~m}, 1 \mathrm{H}), 7.80(\mathrm{~s}, 3 \mathrm{H}), 7.70(\mathrm{~s}, 2 \mathrm{H}), 7.59(\mathrm{~d}, 2 \mathrm{H}, J=$ $8.0 \mathrm{~Hz}), 7.00-7.26(\mathrm{~m}, 8 \mathrm{H})$

Polymer $5 \mathbf{b 1}\left(400 \mathrm{MHz}, \mathrm{CDCl}_{3}\right): \delta(\mathrm{ppm}) 8.63(\mathrm{~m}, 1 \mathrm{H}), 7.83(\mathrm{~m}, 5 \mathrm{H}), 7.73-7.57(\mathrm{~m}, 6 \mathrm{H}), 7.20(\mathrm{~m}$, $4 \mathrm{H})$.

Polymer 5g $\left(\mathrm{CDCl}_{3}, 400 \mathrm{MHz}\right): \delta 8.59(\mathrm{~m}, 1 \mathrm{H}), 7.78(\mathrm{~s}, 3 \mathrm{H}), 7.68-7.59(\mathrm{~m}, 4 \mathrm{H}), 7.46-7.35(\mathrm{~m}, 4 \mathrm{H})$, $7.13(\mathrm{~m}, 2 \mathrm{H}), 7.03(\mathrm{~m}, 2 \mathrm{H})$.

Synthesis of Polymer 5b2: A mixture of $0.5 \mathrm{~g}(2.1 \mathrm{mmol})$ of DHPZ, $0.6548 \mathrm{~g}(2.1 \mathrm{mmol})$ of 4,4'-dibromobiphenyl, $0.4055 \mathrm{~g}(3.0 \mathrm{mmol})$ of potassium carbonate, sulfolane $(6 \mathrm{~mL})$ and chlorobenzene $(10 \mathrm{~mL})$ was charged to a $25 \mathrm{~mL}$, 3-necked round-bottomed flask fitted with a Dean-Stark trap, condenser, inert gas inlet, magnetic stirrer. The temperature of the mixture was raised to $145^{\circ} \mathrm{C}$ to dehydrate the reaction mixture. When no further water could be collected, the 
mixture was heated to $200{ }^{\circ} \mathrm{C}$ and the residual chlorobenzene in the reaction mixture was removed by distillation. Then the mixture was cooled to $190{ }^{\circ} \mathrm{C}$ (or $\left.150{ }^{\circ} \mathrm{C}\right)$ and $0.39 \mathrm{~g} \mathrm{of} \mathrm{Cu}\left(\mathrm{PPh}_{3}\right)_{3} \mathrm{Br}(20$ mol\% of DHPZ), which was produced as described in the literature, was added. The reaction mixture was maintained at $190{ }^{\circ} \mathrm{C}$ for $72 \mathrm{hr}$. The brown reaction solution was then quenched in a stirred solution of methanol with dilute hydrogen chloride. The work-up was the same as the polymer 5a3.

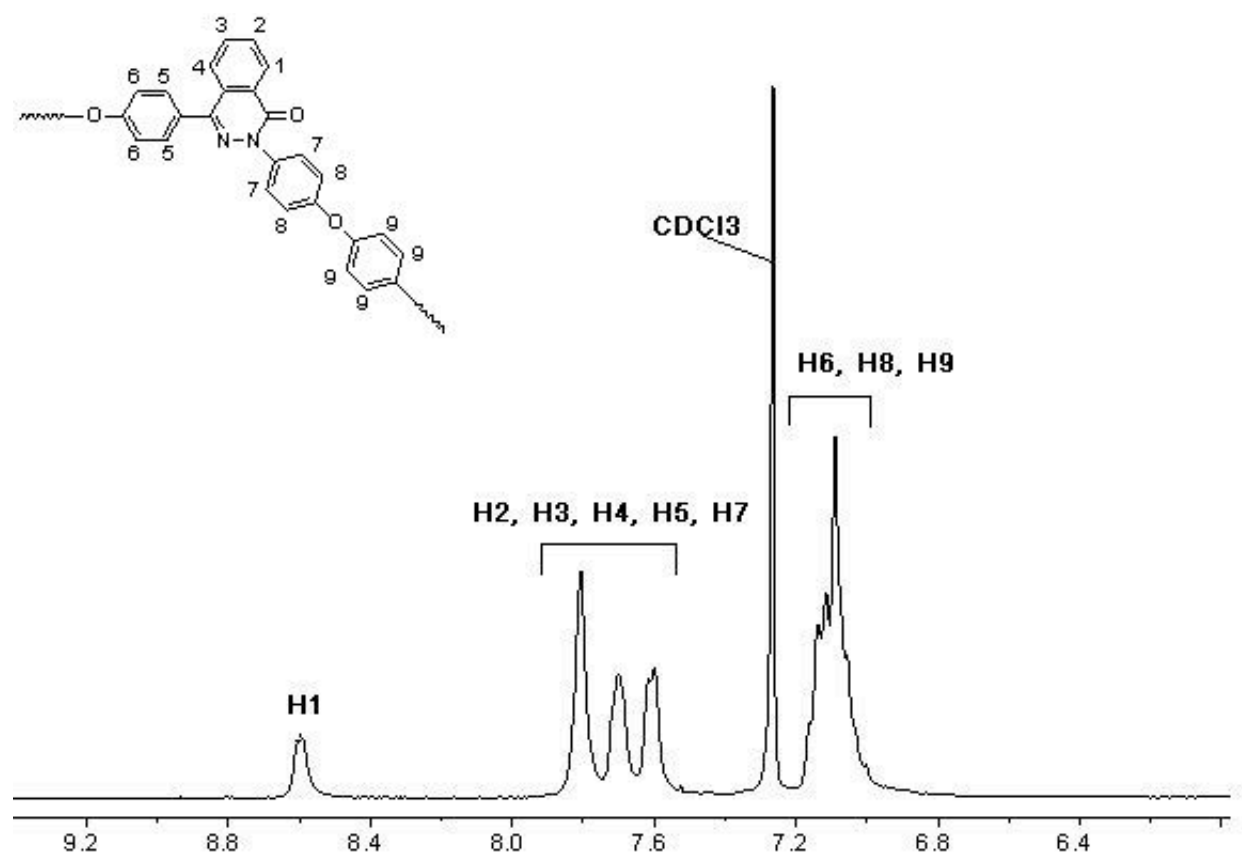

Figure 1. $400 \mathrm{MHz}{ }^{1} \mathrm{H}$ NMR spectrum of Polymer $\mathbf{5 a 3}$ in $\mathrm{CDCl}_{3}$ 


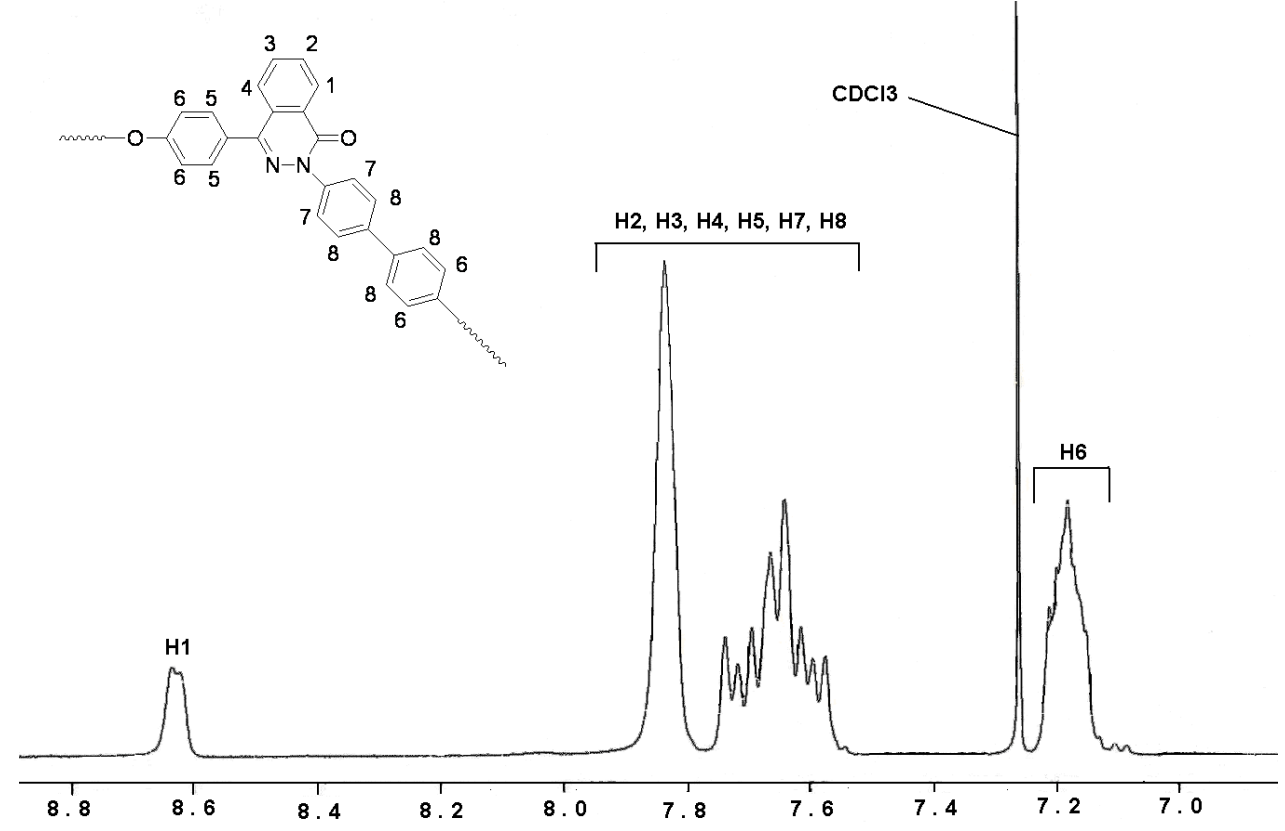

Figure 2. $400 \mathrm{MHz}{ }^{1} \mathrm{H}$ NMR spectrum of Polymer $\mathbf{5 b 1}$ in $\mathrm{CDCl}_{3}$

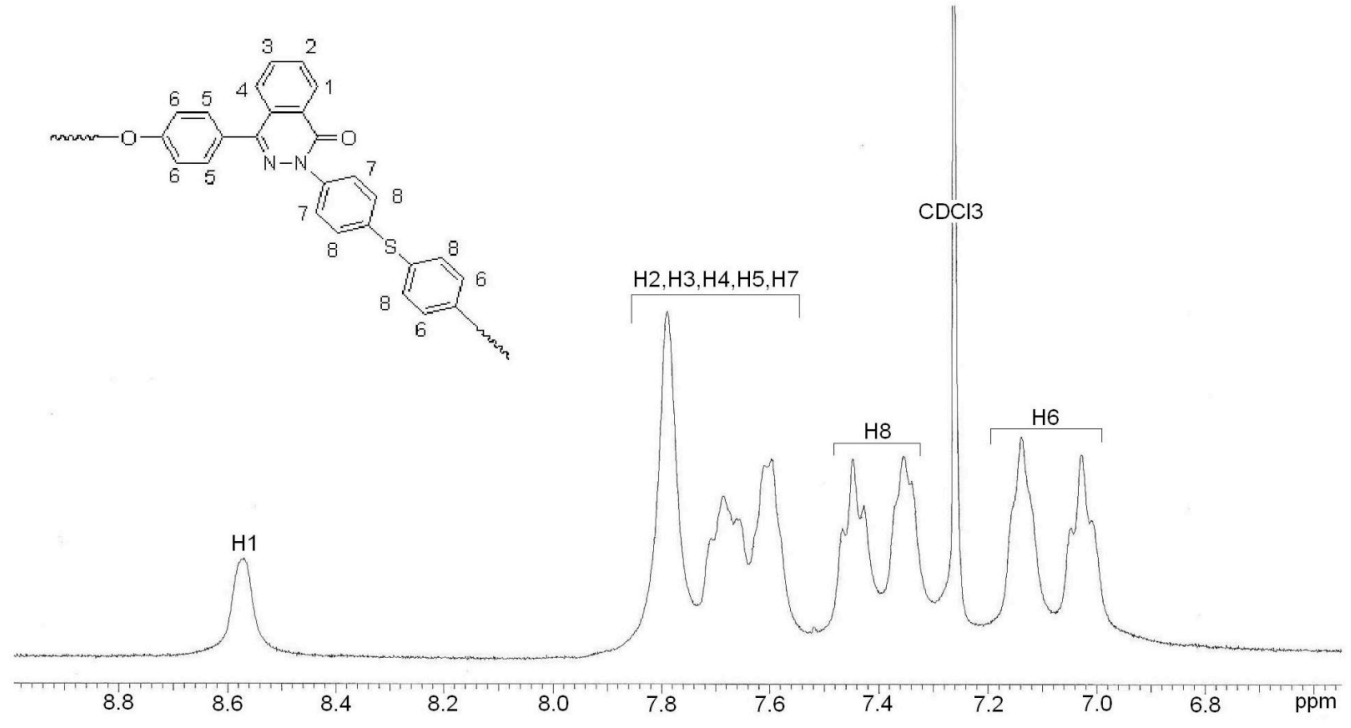

Figure 3. $400 \mathrm{MHz}{ }^{1} \mathrm{H}$ NMR spectrum of Polymer $\mathbf{5 g}$ in $\mathrm{CDCl}_{3}$ 